\title{
Applications of simulation technique on debris-flow hazard zone delineation: a case study in Hualien County, Taiwan
}

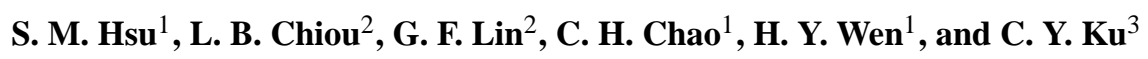 \\ ${ }^{1}$ Geotechnical Engineering Research Center, Sinotech Engineering Consultants, Inc., Taipei, Taiwan \\ ${ }^{2}$ Department of Civil engineering, National Taiwan University, Taipei, Taiwan \\ ${ }^{3}$ Department of Harbour and River Engineering, National Taiwan Ocean University, Keelung, Taiwan
}

Received: 23 October 2009 - Revised: 12 February 2010 - Accepted: 16 February 2010 - Published: 23 March 2010

\begin{abstract}
Debris flows pose severe hazards to communities in mountainous areas, often resulting in the loss of life and property. Helping debris-flow-prone communities delineate potential hazard zones provides local authorities with useful information for developing emergency plans and disaster management policies. In 2003, the Soil and Water Conservation Bureau of Taiwan proposed an empirical model to delineate hazard zones for all creeks (1420 in total) with potential of debris flows and utilized the model to help establish a hazard prevention system. However, the model does not fully consider hydrologic and physiographical conditions for a given creek in simulation. The objective of this study is to propose new approaches that can improve hazard zone delineation accuracy and simulate hazard zones in response to different rainfall intensity. In this study, a two-dimensional commercial model FLO-2D, physically based and taking into account the momentum and energy conservation of flow, was used to simulate debris-flow inundated areas.
\end{abstract}

Sensitivity analysis with the model was conducted to determine the main influence parameters which affect debris flow simulation. Results indicate that the roughness coefficient, yield stress and volumetric sediment concentration dominate the computed results. To improve accuracy of the model, the study examined the performance of the rainfallrunoff model of FLO-2D as compared with that of the HSPF (Hydrological Simulation Program Fortran) model, and then the proper values of the significant parameters were evaluated through the calibration process. Results reveal that the HSPF model has a better performance than the FLO-2D model at peak flow and flow recession period, and the volumetric sediment concentration and yield stress can be estimated by the channel slope. The validation of the model for

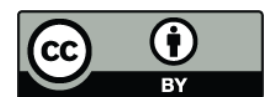

Correspondence to: S. M. Hsu (shihmeng@ sinotech.org.tw) simulating debris-flow hazard zones has been confirmed by a comparison of field evidence from historical debris-flow disaster data. The model can successfully replicate the influence zone of the debris-flow disaster event with an acceptable error and demonstrate a better result than the empirical model adopted by the Soil and Water Conservation Bureau of Taiwan.

\section{Introduction}

Occasional rainfall, steep relief and sufficient debris-flow materials are three major components triggering debris-flow events in a potential debris-flow torrent. Since the topographic, geologic and hydrologic characteristics of Taiwan correspond to the components of debris-flow occurrence, Taiwan is frequently beset by debris flow problems during typhoons and heavy rainfall. These fast-moving flows accompanied by mud and rock are capable of destroying houses and lives, washing out roads and bridges, or obstructing streams and roadways. To mitigate and manage hazards induced by debris flows, it is necessary to simulate the debris-flow route and deposition process. This simulation outcome is very important for determining a possible affected area, which is an essential element for producing hazard maps (Petrascheck and Kienholz, 2003).

The prediction of debris-flow affected areas may be divided into empirical-statistical and dynamic methods (Rickenmann and Koch, 1997; Rickenmann, 1999; Rickenmann et al., 2003). For instance, Takahashi (1991) presented empirical formulas for the thickness and probable maximum length of debris-flow deposits to delineate debris-flow hazardous areas. Based on experimental data, Shieh and Tsai (1997) built the relationships among the maximum length, width and thickness of debris-flow affected areas. In order to consider uncertainty on the probable maximum length, width

Published by Copernicus Publications on behalf of the European Geosciences Union. 


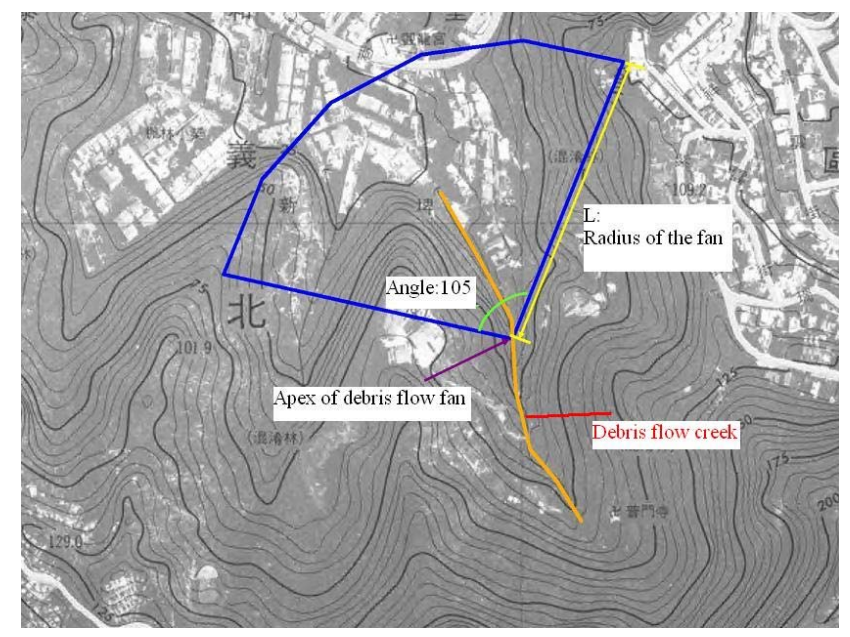

Fig. 1. Debris flow fan delineated by Iketani and Uehera equation.

and thickness, Lin et al. (2004) developed a reliability based methodology for the delineation of debris-flow deposition areas. At the same time, many authors (O'Brien et al., 1993; Han and Wang, 1996; Laigle and Coussot, 1997; Ming and Fread, 1999; Cetina, 2000; Takahashi, 2001; Sosio et al., 2007) utilized dynamic approaches to develop various numerical models for the simulation of debris flows based on different rheological models. By comparing both methods, the advantage of empirical-statistical methods is easy to utilize, but can only to be applied to certain conditions. Dynamic approaches are physically based and take into account the momentum and energy conservation of flow. Thus, they usually produce better results than empirical-statistical methods. Nevertheless, a major difficulty in developing dynamic models for a potential hazard area prediction is the choice of the appropriate model parameters.

An empirical method initiated by Iketani and Uehara (1980) for identifying the debris-flow hazard zones was adopted by the Soil and Water Conservation Bureau (SWCB) of Taiwan. This empirical method consists of certain rules, as well as an empirical equation, which is a function of the debris-flow volume and the slope angle below the apex of a debris-flow fan (CSWCS, 2003). The procedure for determining the depositional extent of a debris flow is to firstly assign the location of debris-flow fan apex, which is the highest point where flow is last confined and then spreads out as sheetflood, debris slurries, or in multiple channels along uncertain paths, such as the mouth of the valley or downstream of the topographic apex. Subsequently, the debris-flow fan is drawn from the apex point with a radius of the fan and 105 degree of angle as shown in Fig. 1, in which the radius L is given as the following equation:

$\log (L)=0.42 \cdot \log (V \cdot \tan \theta)+0.935$

$L$ is named as the depositional length as well; $\theta$ is the slope angle at the downstream of a potential debris-flow creek; $V$ is the debris-flow volume ( $V$ is determined by the empirical equation $V=70.992 A^{0.61} ; A$ is the area of a debris-flow watershed, $\mathrm{km}^{2}$ ). Equation (1) shows that the depositional length, which is derived from a fully empirical approach, depends on the slope angle and the area of watershed and does not vary with rainfall intensity. However, the delineating zone for each potential debris-flow torrent is often underestimated or overestimated because of a comparison made with data from aerial photos of historical debris-flow disaster events. In order to improve the accuracy of the empirical model for predicting debris-flow hazard zones, it is necessary to establish a model which can simulate hazard zones under different rainfall intensities to maintain a reliable level.

In this study, a two-dimensional commercial model FLO-2D (O'Brien et al., 2006), which is physically based and takes into account the momentum and energy conservation of flows, was used to predict areas potentially endangered by debris flows for downstream guarded areas of potential debris-flow creeks. Sensitivity analysis with the model was conducted to determine the main influential parameters which affect debris-flow simulation. To improve the accuracy of the model, the study examined the performance of the rainfall-runoff model of FLO-2D as compared with that of the HSPF (Hydrological Simulation ProgramFortran) model, and then the proper values of the significant parameters were evaluated with the calibration process. Other parameters used in the model were retrieved from the literature and field investigations. The validation of the proposed model for simulating debris-flow hazard zones was confirmed by a comparison of field evidence from historical debris-flow disaster data.

\section{The study area}

The study area was located in Hualien County, on the eastern coast of Taiwan, as shown in Fig. 2. Hualien County faces the immense Pacific Ocean to the east and leans against the grand Central Mountain Range in the west. The area is on the boundary of the Philippine and Eurasian Plates. Because the plates collide, the county has plenty of metamorphic rock. Because of strong erosion, the sea terraces, river terraces, alluvial fans, meanders and a river valley basin can be easily found in this area.

Hualien County is mountainous with a long and narrow territory. The area below a $100 \mathrm{~m}$ elevation occupies $9 \%$ of County's land area. Terrain with a hillslope angle less than $5 \%$ covers $12.7 \%$. Because of the limited plain areas, urban development on slopeland has become inevitable. Besides, typhoons with heavy rainfall frequently attack Hualien County every year during the period mainly from June to October and bring bountiful rainfall. Because of these geomorphological and hydrological characteristics, landslides, 


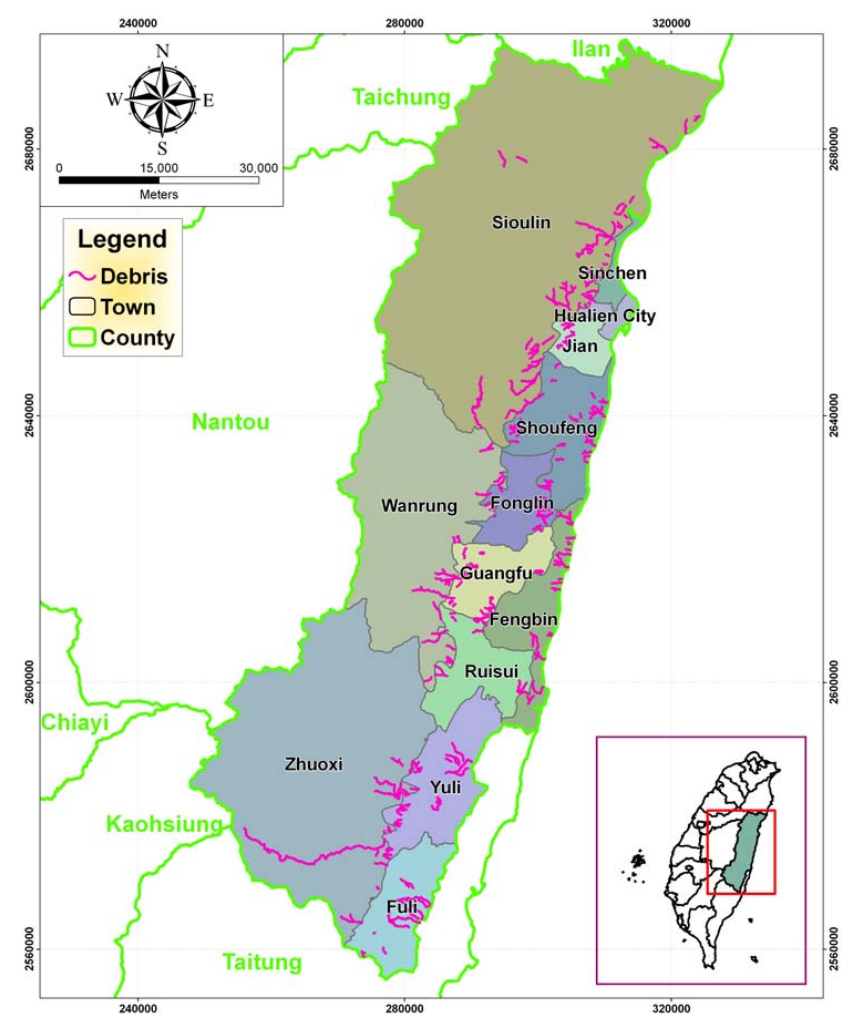

Fig. 2. Location of study area and distribution of potential debrisflow creeks in Hualien County.

debris flows and flood disasters prevail in the region during typhoon season. Figure 2 shows the distribution of potential debris-flow creeks in Hualien County. Out of 1503 potential debris-flow creeks in Taiwan, the county contains 162 creeks spread throughout 13 towns. In the past, debris flows occurred in some of the potentially debris-flow-prone creeks, especially in the villages of Tonmeng, Dasing, Fongyi and Jiancing and which resulted in casualties and serious property damage. Figure 3 shows a devastating debris-flow calamity caused by Typhoon Toaji in 2001 which occurred in Dashing village. The typhoon brought heavy rainfall with the maximum rainfall intensity of about $101 \mathrm{~mm} / \mathrm{h}$ and a 3-day accumulated rainfall of about $922 \mathrm{~mm} / \mathrm{h}$, triggering landslides that produced a large amount of slope material which transformed into debris flows. According to the official disaster statistics issued by the Hualien office of the SWCB, the event produced approximately 150 million $\mathrm{m}^{3}$ of rock and debris that flowed down to guarded areas and killed 43 people, as well as buried 150 houses. It is these types of calamities that make the study of debris flows an urgent and challenging task in the region.
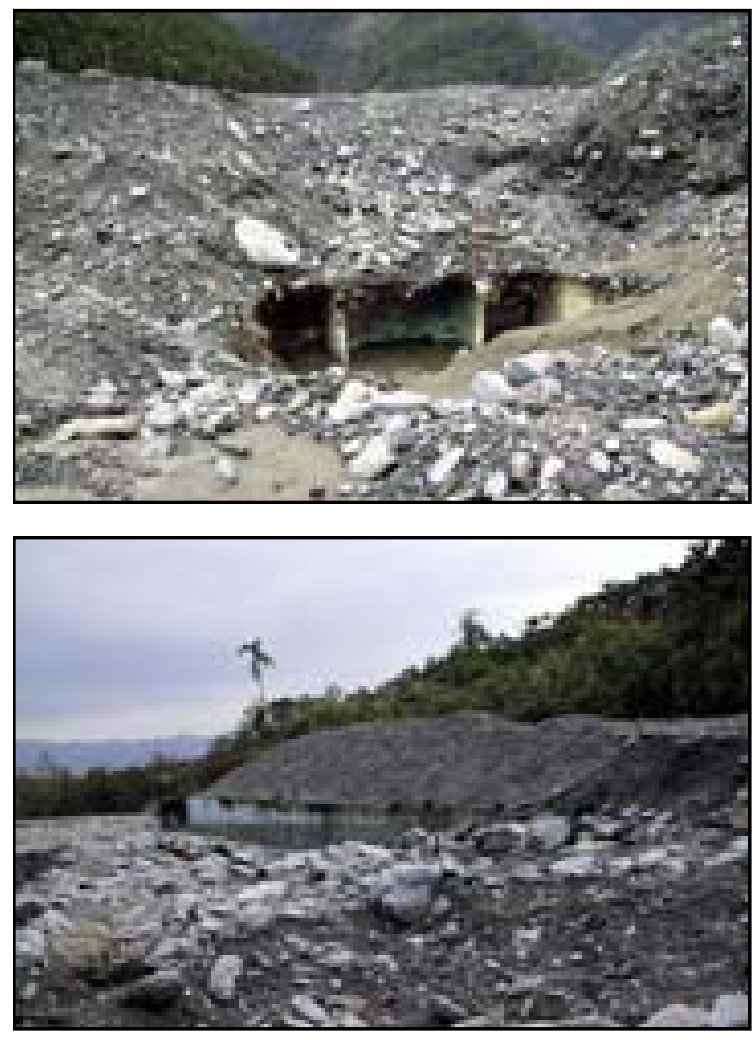

Fig. 3. Debris flow disaster caused by Typhoon Toaji occurring on 28 July 2001 in Dashing village.

\section{Methods}

The location and size of an affected area induced by debris flow in a potential debris-flow creek usually depend on hydrologic and physiographical conditions of the creek. A more suitable model to predict the debris-flow hazard zone should be dynamic and should take into account these conditions. The method used and developed in this study was intended for improving drawbacks and limitations of the empirical method adopted by the SWCB of Taiwan. The study proposes a new debris-flow hazard zone delineation procedure to enhance the accuracy of the current method.

\subsection{Numerical model}

With the development of simulation techniques, numerical modelling has become an increasingly important tool to simulate behaviour and characteristics of debris flows. Depending on the type of debris flow and the debris flow process, a numerical tool with an appropriate rheological model must be chosen. A numerical model, FLO-2D, developed by O'Brien (2006) was selected for the purpose of the present study. The rheological model adopted in the FLO-2D is a well-known quadratic shear stress model which 
can describe the continuum of flow regimes from viscous to turbulent/dispersive flow (O'Brien et al., 1993). This model can avoid the modelling problem of not knowing the flow regime in advance (Cetina et al., 2006).

FLO-2D has been successfully used for practical cases of debris flow simulations by many researchers (Julien and O'Brien, 1997; Garcia and Lopez, 2005; Lin et al., 2005; Cetina et al., 2006). O'Brien et al. (2006) also reported that FLO-2D has been applied in a list of countries including the United States, Italy, Switzerland, Austria, Mexico, Ecuador, Venezuela, South Korea, Taiwan and Thailand. Due to its acceptable applicability, the FLO-2D model is on FEMA's (Federal Emergency Management Agency, USA) list of approved hydraulic models for both riverine and overland flow (alluvial fan) flood studies. The SWCB of Taiwan has approved the model for debris flow study as well. Thus, the present paper chose the model to serve the purpose of this study.

The FLO-2D model is a two-dimensional flood routing model that can simulate flows over complex topographies and roughness on urbanized alluvial fans. Hyperconcentrated sediment flows, such as mudflows and the transition from water flows to fully developed mud and debris flows, can be simulated as well.

FLO-2D routes a flood hydrograph using the full dynamic wave momentum equation to accurately predict the area of inundation. The fluid viscous and yield stress terms are accounted for in the model for hyperconcentrated sediment flows. The basic equations used in the model include the continuity equation

$$
\frac{\partial h}{\partial t}+\frac{\partial h u}{\partial x}+\frac{\partial h v}{\partial y}=i
$$

and the two-dimensional equations of motion

$$
\begin{aligned}
& S_{\mathrm{fx}}=S_{\mathrm{ox}}-\frac{\partial h}{\partial x}-\frac{u}{g} \frac{\partial u}{\partial x}-\frac{v}{g} \frac{\partial u}{\partial y}-\frac{1}{g} \frac{\partial u}{\partial t} \\
& S_{\mathrm{fy}}=S_{\mathrm{oy}}-\frac{\partial h}{\partial y}-\frac{v}{g} \frac{\partial v}{\partial y}-\frac{u}{g} \frac{\partial v}{\partial x}-\frac{1}{g} \frac{\partial v}{\partial t}
\end{aligned}
$$

in which $h=$ flow depth; $u$ and $v=$ depth-averaged velocity components along $\mathrm{x}$ - and $\mathrm{y}$-coordinates; $i=$ excess rainfall intensity; $S_{\mathrm{fx}}$ and $S_{\mathrm{fy}}=$ friction slope components along xand y-coordinates; $S_{\mathrm{ox}}$ and $S_{\mathrm{oy}}=$ bed slope components along $\mathrm{x}$ - and y-coordinates; and $g=$ gravity acceleration.

The total friction slope can be expressed as

$S_{\mathrm{f}}=S_{\mathrm{y}}+S_{\mathrm{v}}+S_{\mathrm{td}}=\frac{\tau_{\mathrm{y}}}{\gamma_{\mathrm{m}} h}+\frac{K \eta w}{8 \gamma_{\mathrm{m}} h^{2}}+\frac{n^{2} w^{2}}{h^{4 / 3}}$

in which $S_{\mathrm{y}}=$ yield slope; $S_{\mathrm{v}}=$ viscous slope; $S_{\mathrm{td}}=$ turbulentdispersive slope; $\gamma_{\mathrm{m}}=$ specific weight of the sediment mixture; $K=$ resistance parameter; $\eta=$ viscosity; $\tau_{\mathrm{y}}=$ yield stress; $w=$ depth-averaged velocity. Equation (5) evaluates rheological behaviour of hyperconcentrated sediment flows.

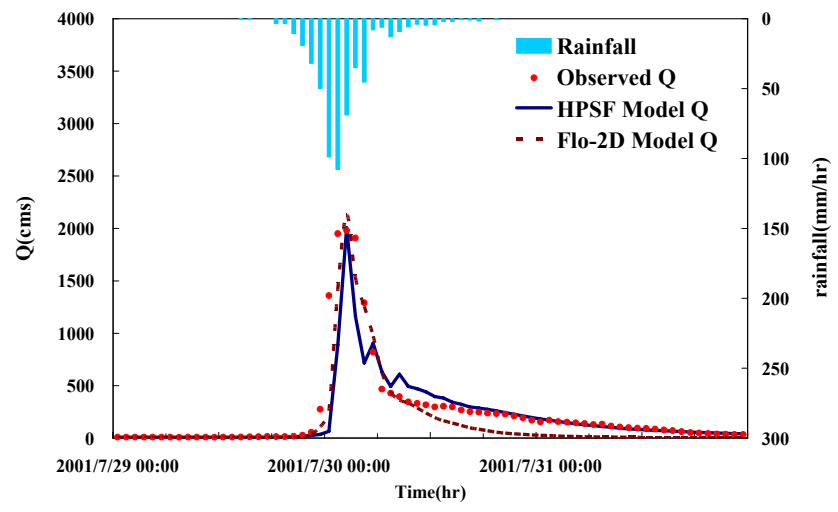

Fig. 4. Comparisons of recorded, FLO-2D and HSPF hydrographs at Wanlishi bridge streamflow station during Typhoon Toaji.

In addition, the yield stress $\tau_{\mathrm{y}}$ and the viscosity $\eta$ vary principally with sediment concentration, and can be expressed in empirical relationships as

$\tau_{\mathrm{y}}=\alpha_{1} e^{\beta_{1} C}$

$\eta=\alpha_{2} e^{\beta_{2} C}$

in which $C=$ volumetric sediment concentration; $\alpha_{i}$ and $\beta_{i}=$ empirical coefficients defined by laboratory experiment.

Data required for the model simulation include a digital terrain model, channel geometry, estimates of channel and floodplain roughness, inflow flood hydrographs or rainfall and rheological properties of the sediment water mixture. For the rheological properties, the volumetric sediment concentration and yield stress are not easy to measure from a field investigation, especially since 162 potential debris-flow creeks exist in Hualien County Selecting representative values for the above parameters for each debris-flow creek is critical. They can help characterise debris-flow on alluvial fans in a range of varied environments.

In addition, the study examined the performance of the rainfall-runoff model of FLO-2D as compared with that of the HSPF (Hydrological Simulation Program-Fortran) model which is a continuous watershed simulation model that produces a timeline of water quantity and quality (Johanson et al., 1980). Both models were applied to simulate rainfallrunoff in the Wanlishi watershed of Hualien County. Results showed the HSPF model had a better performance than the FLO-2D model at peak flow and flow recession periods as shown in Fig. 4. To enhance the accuracy of debris-flow simulation, the HSPF model - instead of using the rainfall-runoff module in the FLO-2D model - was adopted to compute an inflow hydrograph. 


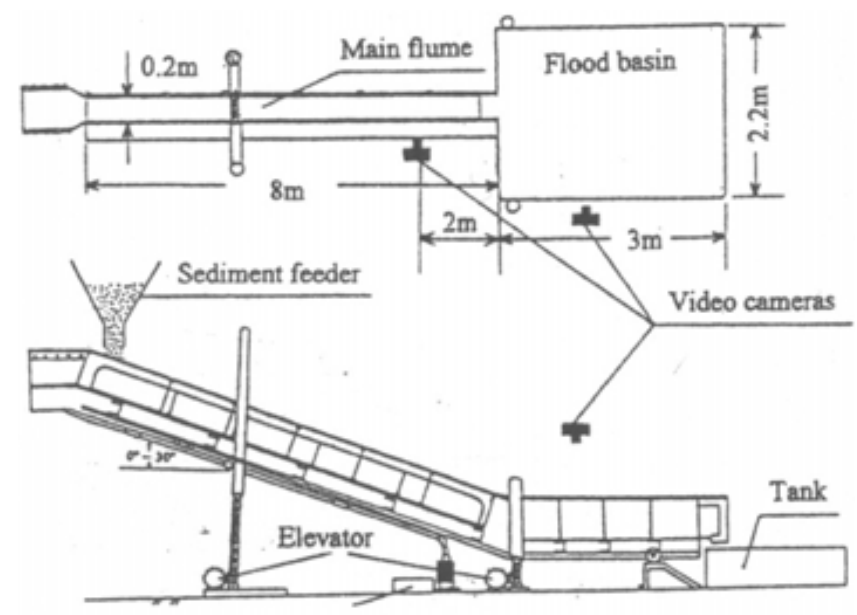

(a)

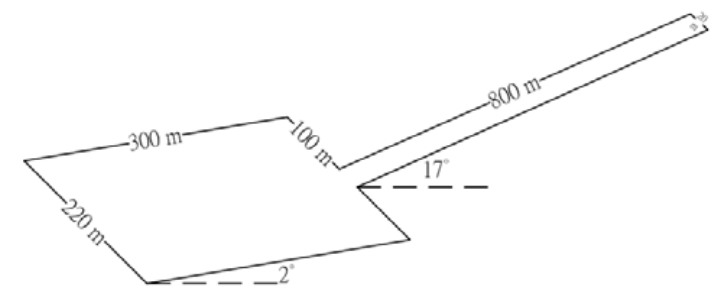

(b)

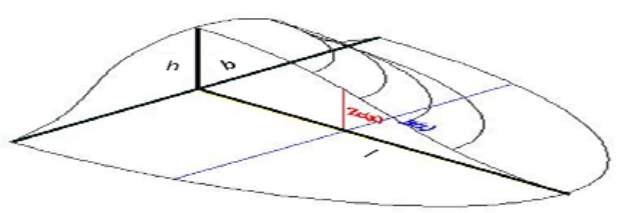

(c)

Fig. 5. (a) Schematic of numerical flume from both top and side views; (b) flume dimension and gradients at upstream and downstream of the flume; (c) Schematic of the maximum depositional depth $(h)$, maximum depositional length $(l)$ and maximum depositional width $(b)$ in the deposition area.

Table 1. Model sensitivity to various parameters.

\begin{tabular}{lccccc}
\hline Parameter & $\begin{array}{c}\text { Basic } \\
\text { case }\end{array}$ & Range & $\begin{array}{c}h-h_{\text {basic }} / h_{\text {basic }} \\
(\%)\end{array}$ & $\begin{array}{c}l-l_{\text {basic }} / l_{\text {basic }} \\
(\%)\end{array}$ & $\begin{array}{c}b-b_{\text {basic }} / b_{\text {basic }} \\
(\%)\end{array}$ \\
\hline$\tau_{\mathrm{y}}(\mathrm{Pa})$ & 1500 & $800 \sim 3000$ & $-46 \% \sim 36 \%$ & $48 \% \sim-39 \%$ & $13 \% \sim-13 \%$ \\
$\eta(\mathrm{Pa}-\mathrm{s})$ & 10 & $0.1 \sim 30$ & $-2 \% \sim 1 \%$ & $-0.01 \% \sim 0.01 \%$ & $-0.01 \% \sim 0.01 \%$ \\
$G_{\mathrm{S}}$ & 2.65 & $2.00 \sim 3.00$ & $8 \% \sim-6 \%$ & $-19 \% \sim 5 \%$ & $-12 \% \sim 6 \%$ \\
$n$ & 0.2 & $0.01 \sim 0.40$ & $-15 \% \sim 8 \%$ & $5 \% \sim-33 \%$ & $0.01 \% \sim-24 \%$ \\
$C_{\mathrm{V}}$ & 0.5 & $0.30 \sim 0.70$ & $-19 \% \sim 115 \%$ & $-33 \% \sim 47 \%$ & $-29 \% \sim 29 \%$ \\
$K$ & 1000 & $100 \sim 10000$ & $-2 \% \sim 2 \%$ & $-0.01 \% \sim 0.01 \%$ & $-0.01 \% \sim 0.01 \%$ \\
\hline
\end{tabular}

Note: the last three columns show differences from the basic case in percent.

\subsection{Sensitivity analysis}

The purpose of performing a sensitivity study is to determine the main influence parameters which affect debris-flow simulation. For these parameters, adopted values in simulation should be carefully calibrated in order to ensure accurate results. A numerical regular flume, as shown in Fig. 5, was used as a tool to study sensitivity of various parameters used in the FLO-2D model. The study tested computational variations by comparing the maximum depositional depth $(h)$, maximum depositional length $(l)$ and maximum depositional width $(b)$ from a basic case for six parameters, including: yield stress, dynamic viscosity, specific gravity, roughness coefficient $n$, volumetric sediment concentration and the resistance parameter for laminar flow. The study chose a set of parameters as a basic case, as shown in Table 1, to proceed with the parametric study. The influence of various param- eters is summarized in Table 1. It was found that the yield stress, roughness coefficient $n$ and volumetric sediment concentration have a relatively large influence on the simulated results as compared with other testing parameters. The result is identical to that of other researches (Lin et al., 2005; Arattano et al., 2006; Sosio et al., 2007).

\subsection{Determination of rheological parameters of debris flow}

Based on the aforementioned sensitivity analysis result, while examining parameters related to debris flows, it is important to identify the volumetric sediment concentration and yield stress, which dominate the behaviour of debris flows. This study utilized an empirical equation and the back-analysis technique to determine the input values for the two variables in a given potential debris-flow creek. 


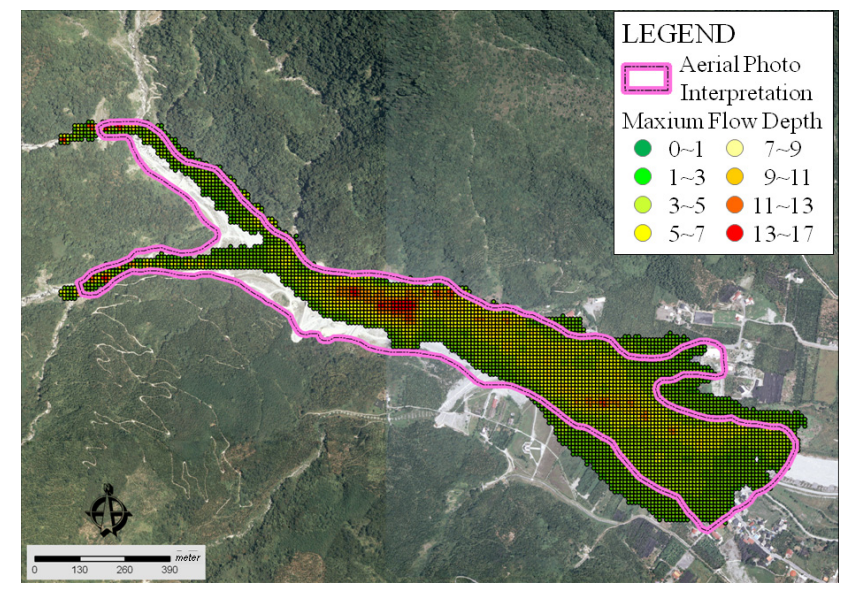

Fig. 6. Comparison of debris-flow affected area from aerial photo interpretation and model simulation in the Haulien 061 creek in Dasing village.

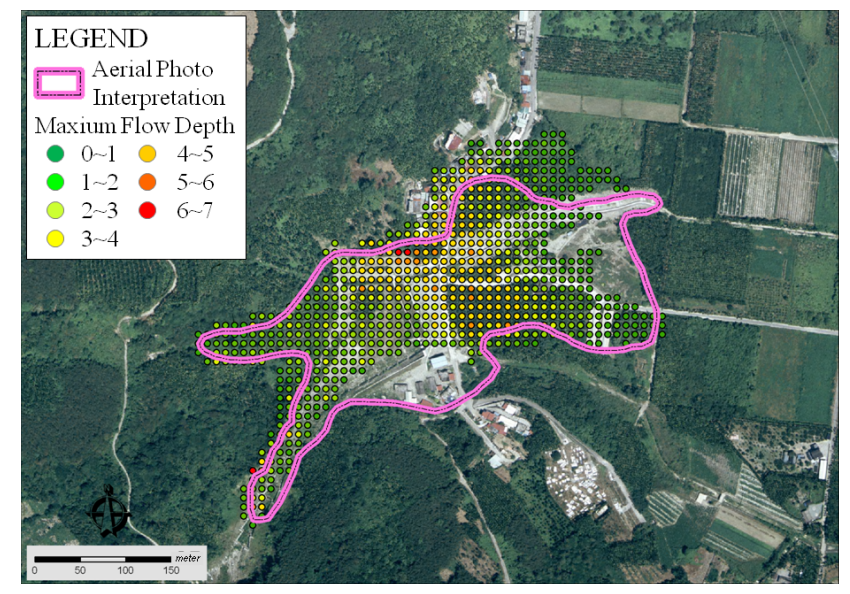

Fig. 7. Comparison of debris-flow affected area from aerial photo interpretation and model simulation in the Haulien 069 creek in Jiancing village.

The volumetric sediment concentration $\left(C_{\mathrm{v}}\right)$ is defined as the volume of sediment divided by volume of water plus sediment. By introducing Takahashi's equilibrium concentration formula (Takahashi, 1980), the volumetric sediment concentration can be estimated by the equilibrium concentration $\left(C_{\mathrm{D}}\right)$ divided by the volume concentration of solid fraction on the bed $\left(C_{\mathrm{b}}\right)$, in which $C_{\mathrm{b}}$ can be estimated from the porosity of solid fraction on the bed; and $C_{\mathrm{D}}$ is given as the following equation,

$C_{\mathrm{D}}=\frac{\rho_{\mathrm{w}} \tan \theta}{\left(\rho_{\mathrm{s}}-\rho_{\mathrm{w}}\right)(\tan \phi-\tan \theta)}$

where $\theta$ is the inclined angle of the channel bed and $\phi$ is the internal friction of debris; $\rho_{\mathrm{s}}$ and $\rho_{\mathrm{w}}$ are densities of solids

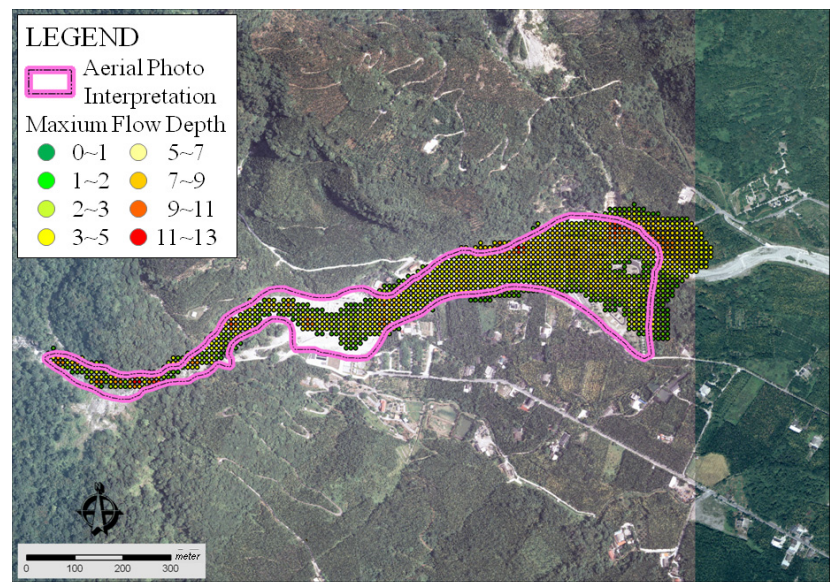

Fig. 8. Comparison of debris-flow affected area from aerial photo interpretation and model simulation in the Haulien A112 creek in Fongyi village.

and water, respectively. Since the equilibrium concentration is dependent on the bed inclination, the volumetric sediment concentration in a given potential debris-flow creek is a function of the channel slope.

For the determination of yield stress, the study utilized real cases to calibrate the variable by means of back analyses to fit the field evidence from historical debris-flow disaster data. The calibration was made using data from the past debris-flow events, which occurred in three debris-flowprone creeks (Hualien 061, Hualien 069, and Hualien A112, respectively) in Hualien County during the Typhoon Toraji (July 2001). Parameters used in the model calibration were retrieved from the literature and field investigations (Sinotech, 2007). By adjusting values of the yield stress in the model to fit the observed hazard zone, Figs. 6, 7 and 8 show comparison results of debris-flow affected areas from aerial photo interpretation and model simulation in the creeks Haulien 061, Hualien 069 and Haulien A112, respectively. The solid polygon in three figures represents debris-flow influenced areas delineated from aerial photos. The calibration results indicate the error between simulated and observed is within $10 \%$ with the check of influenced areas and $20 \%$ with the check of overlapped area referred to the area of polygon.

Table 2 shows the calibration results of the yield stress for three debris-flow creeks. The drainage area, average slope of debris-flow fan apex and lithology on the creek bed for each creek are also listed in the table. Comparing the yield stress with physiographical characteristics of the creeks, it turned out that the yield stress varied with the slope angle of debris flow fan apex only. The yield stress tended to increase with the slope angle. The lithology could be relevant to the yield stress, because it controls the rheology of materials; however in this case study, it is not relevant because it does not change 
Table 2. Calibration results of yield stress for three potential debris-flow creeks.

\begin{tabular}{lllll}
\hline Name of creek & Lithology & $\begin{array}{l}\text { Drainage } \\
\text { area } \\
\text { (ha) }\end{array}$ & $\begin{array}{l}\text { Slope angle at } \\
\text { the fan apex } \\
\text { (degree) }\end{array}$ & Yield stress \\
(Pa)
\end{tabular}

significantly. Based on the outcome, the results suggest that the relationship between the yield stress and the slope angle can be classified into three different categories, as shown in Table 3. The table is beneficial to the selection of the yield stress in modelling a debris-flow hazard zone with different slope angles for creeks with metamorphic rock.

\subsection{Simulation procedure of debris flow}

Since the impact of debris flow often threatens the downstream area where the debris starts to deposit, the deposition and propagation of debris flow in the deposition area are the main interest in this paper. Some assumptions such as homogeneous fluid, non-erodible bed, and constant rheology along the channel and in time were made in the simulation. The procedure for determining the depositional extent of debris flow is given as follows:

1. Assign the location of debris-flow fan apex based on the highest point where the flow was last confined, then spread out as sheetflood, debris slurries, or in multiple channels along paths that are uncertain, such as the mouth of valley or downstream of the topographic apex. The location of fan apex for a given debris-flow-prone creek can be obtained from field investigation.

2. Prepare input data which can be grouped into the categories of geometry, hydrology and sediment. Geometric data include DEMs of watersheds with a resolution of $5 \mathrm{~m}$ by $5 \mathrm{~m}$, channel and floodplain roughness coefficient $n$ values which can be referred to from the FLO-2D user's manual (O'Brien et al., 2006) and other data such as channel geometry. Hydrologic data include rainfall data and input data for the used rainfallrunoff model (herein, HSPF). Sediment data include yield stress, dynamic viscosity, specific gravity, volumetric sediment concentration and resistance parameter $K$ for laminar flow.

3. Produce an inflow hydrograph for a simulated watershed using the HSPF rainfall-runoff model. In addition, hydrological analysis, including rainfall frequency analysis and design storms, can be done in this step.
Table 3. Relationship between yield stress and bed slope.

\begin{tabular}{cc}
\hline $\begin{array}{c}\text { Slope angle at } \\
\text { the fan apex } \\
\text { (degree) }\end{array}$ & $\begin{array}{c}\text { Suggested } \\
\text { yield stress } \\
(\mathrm{Pa})\end{array}$ \\
\hline$>16$ & 2500 \\
$12 \sim 16$ & 1200 \\
$<12$ & 800 \\
\hline
\end{tabular}

The results can be used to simulate a debris flow for extreme events in the future if needed.

4. Determining the debris flow hydrograph by the bulking factor and resulting inflow hydrograph. The bulking factor $\left(\mathrm{BF}=1 /\left(1-C_{\mathrm{v}}\right)\right)$ can be calculated by assigning the volumetric sediment concentration, which can be determined by Eq. (8) and the value of $C_{\mathrm{b}}$.

5. Proceed with debris-flow simulation by assigning all other required input data and the resulting debris flow hydrograph. From this, the inundated area of debris flow can be obtained. Based on the result, the potential debris-flow hazard zone for a study creek can be delineated.

A flowchart showing the steps for simulation of debris flow using the FLO-2D model can be found in Fig. 9.

\section{Model validation}

\subsection{Debris-flow event description}

On 28 July 2008, Typhoon Fenghung, passing across the eastern part of Taiwan, brought heavy rainfall with a maximum rainfall intensity of about $73.5 \mathrm{~mm} / \mathrm{h}$ and $24-\mathrm{h}$ accumulated rainfall of about $500 \mathrm{~mm}$ at the Shilin Rainfall Station. The accumulated rainfall broke the record based on the statistical data collected from between 1995 and 2008. Consequently, it caused numerous debris flows in Taiwan and 


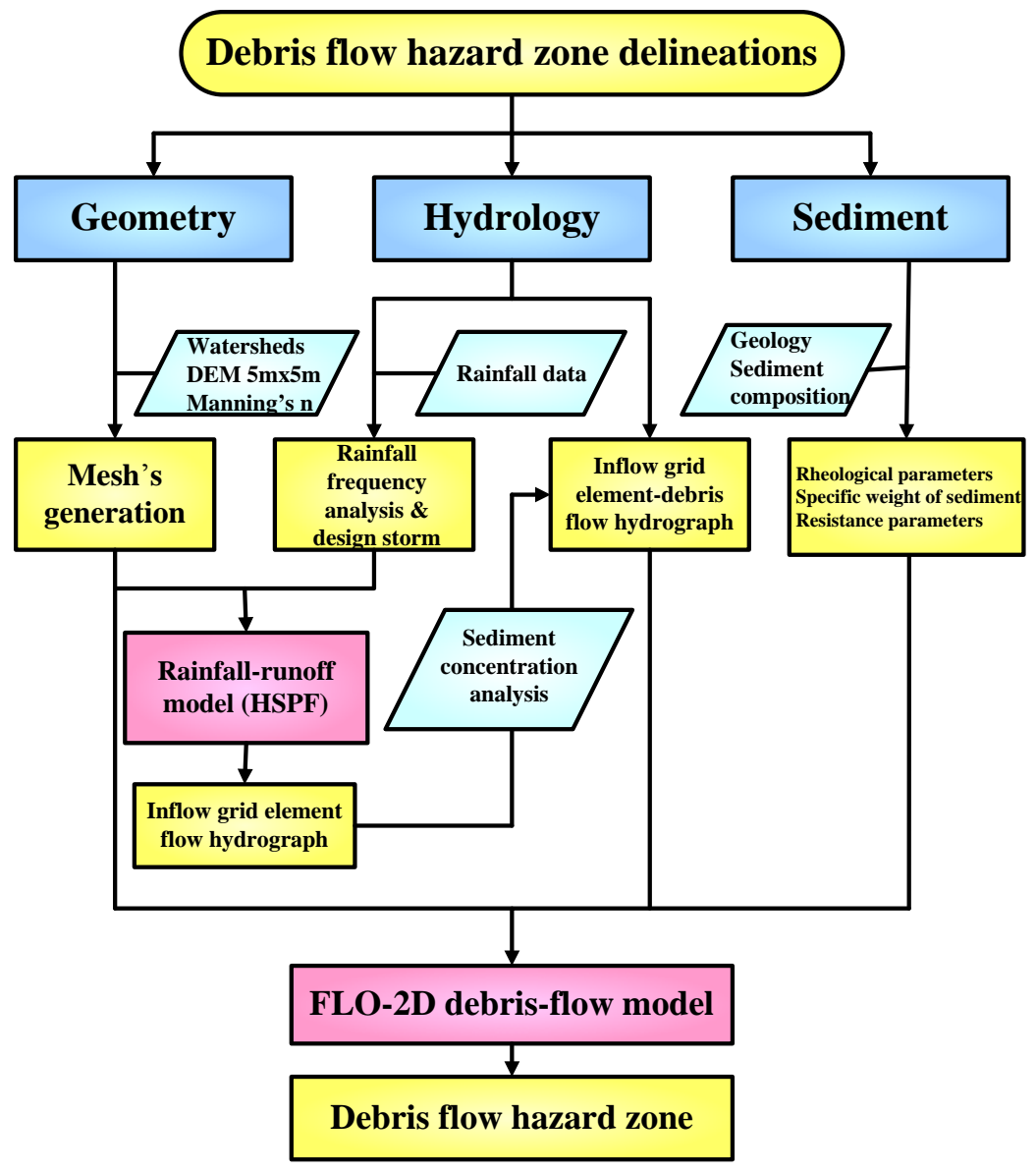

Fig. 9. Flowchart for simulation of debris flow using FLO-2D.

resulted in loss of lives and property. In Hualien County, debris flows occurred in the Hualien A124 creek located in Dama Village and Hualien 072 creek located in Shuhu Village, leading to heavy debris deposits around the outlet of debris-flow creeks. Figures 10 and 11 show the photos before and after Typhoon Fenghung in the Hualien A124 creek and in the Hualien 072 creek, respectively. The after photos were taken one week after the typhoon. One notable difference that occurred after the event was that the riverbed became wider and deeper. The elevation of the riverbed induced by debris deposits caused damage to property and the cross section of an existing bridge.

\subsection{Numerical simulation and model verification}

To verify the accuracy of the presented model, we replicated the debris-flow hazard zones caused by Typhoon Fenghung of the Hualien 124 and Hualien 072 creeks. The proposed numerical model as described in previous sections was applied to simulate the debris-flow hazard zones. The volumetric sediment concentration and yield stress for the two creeks were determined by Eq. (8) and Table 3, respectively.
Other parameters used in the model were obtained from the in situ investigation. Rainfall data for Hualien A124 and Hualien 072 were collected from the rainfall records of the Taian and Shilin Rainfall Stations during the Fenghung Typhoon, respectively.

Figures 12 and 13 show the numerical calculation hazard zones. The maximum flow depths and velocities as well as the simulated sediment volume of the event for each creek can also be obtained in calculations. In the case of Haulien A124, calculation results indicated the simulated sediment volume was approximately $62020 \mathrm{~m}^{3}$; maximum flow velocity was about $13.55 \mathrm{~m} / \mathrm{s}$; an average depth on the maximum flow depth map was about $2.82 \mathrm{~m}$; an average velocity on the maximum flow velocity map is about $1.18 \mathrm{~m} / \mathrm{s}$. For the case of Haulien A072, calculation results indicated the simulated sediment volume was approximately $48259 \mathrm{~m}^{3}$; maximum flow velocity was about $12.76 \mathrm{~m} / \mathrm{s}$; an average depth on the maximum flow depth map was about $1.81 \mathrm{~m}$; an average velocity on the maximum flow velocity map was about $1.84 \mathrm{~m} / \mathrm{s}$. 


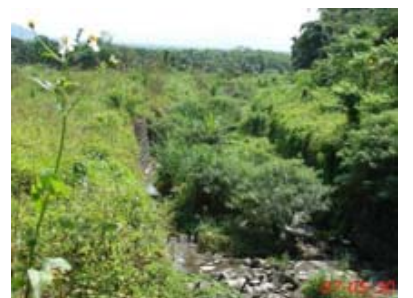

Before

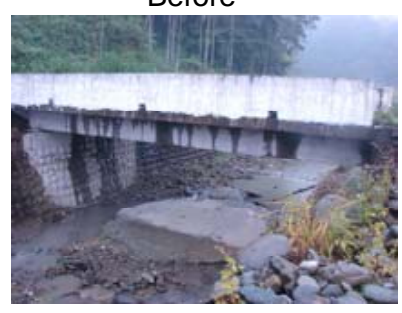

Before

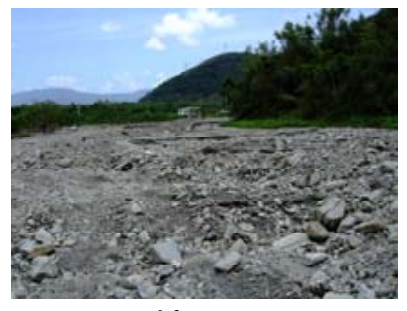

After

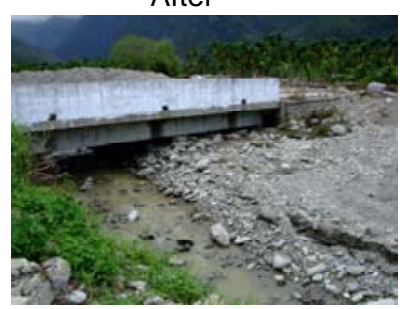

After
Fig. 10. Before and after photos of Typhoon Fenghung in the Hualien A124 creek.

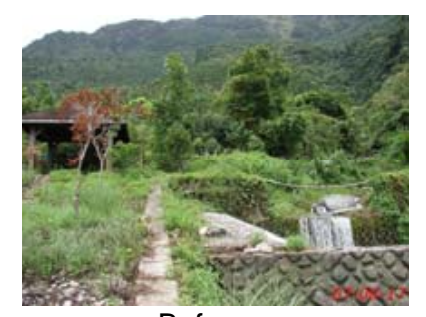

Before

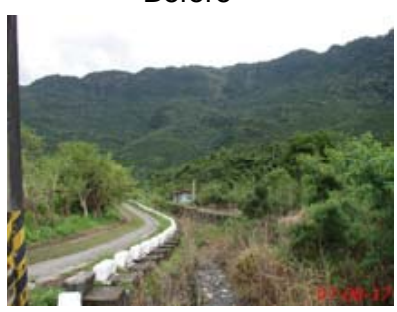

Before

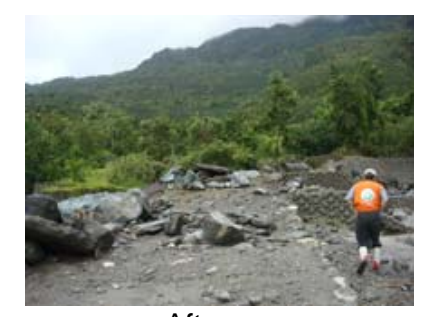

After

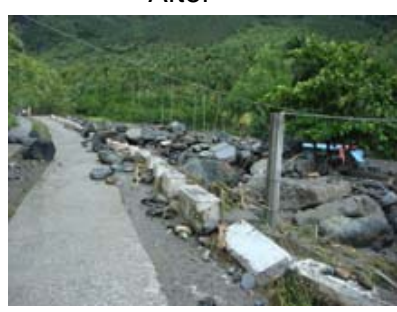

After
Fig. 11. Before and after photos of Typhoon Fenghung in the Hualien 072 creek.

Because of the lack of observable data on sediment yields and flow depths and velocities, the study compared only inundated areas of debris flow between observed and simulated results for the model verification. The model verification results for the case of Haulien A124 indicated the error between simulated and observed was $9.09 \%$, with the check of influenced areas and $13.40 \%$, with the check of the overlapped area referred to in the area of aerial photos interpretation. The presented method can successfully replicate the influential zone of the debris-flow disaster event with an error of less than $15 \%$. The model verification results for the case of Haulien 072 indicated the error between simulated and observed was $9.17 \%$ with the check of influenced areas and $28.27 \%$, with the check of the overlapped area referred

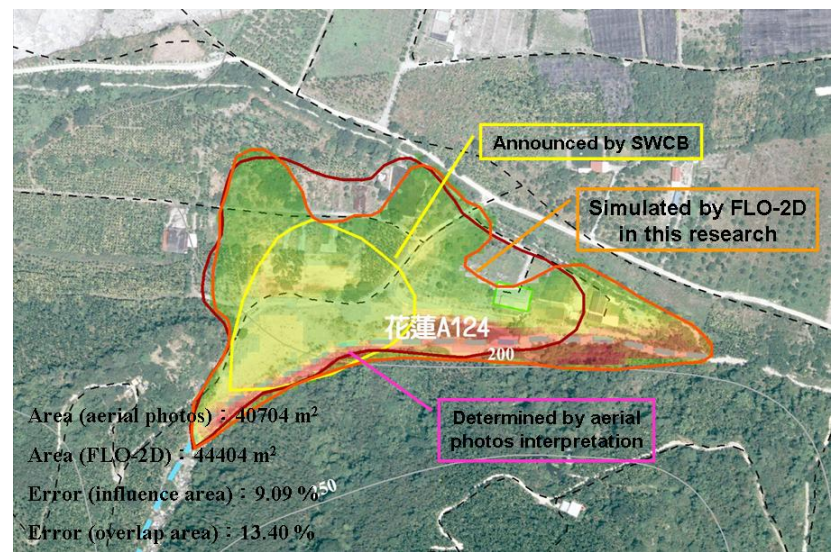

Fig. 12. Comparison of debris-flow hazard zone predicted by SWCB method and presented method for the case of Hualien A124.

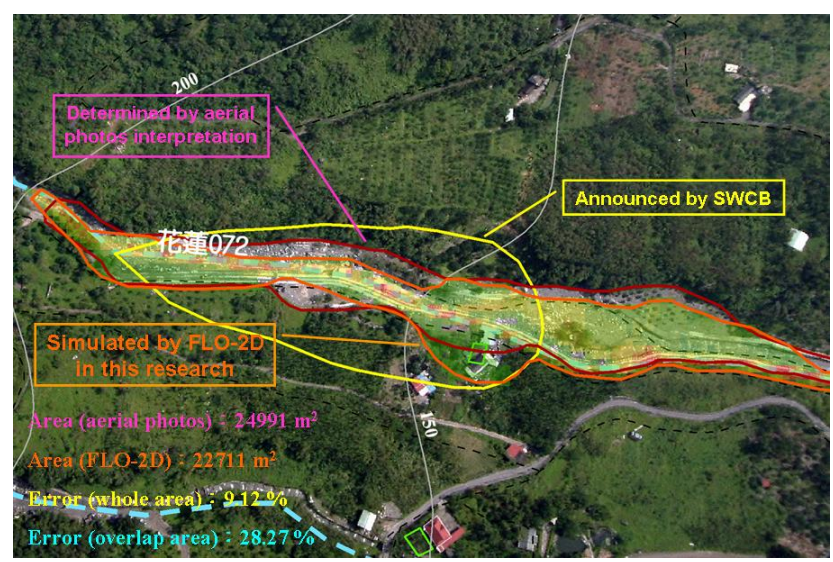

Fig. 13. Comparison of debris-flow hazard zone predicted by SWCB method and presented method for the case of Hualien 072.

to in the area of aerial photos interpretation. The verification result for the case based on the influenced area worked quite well. However, the verification result based on the overlapped area was not as successful. The reason for this may be derived from the limitation of the FLO-2D model on simulating the lateral erosion of the channel bank. The comparisons of debris-flow hazard zones predicted by the SWCB method and the proposed method for the Hualien A124 and Hualien 072 cases were also performed in Figs. 12 and 13, respectively. The debris-flow hazard zone predicted by the SWCB method was underestimated in the Haulien A124 case and overestimated in transverse direction in the Haulien 072 case. This resulted in large errors in identifying the debrisflow hazard zone for debris-flow-prone creeks. 


\section{Conclusions}

The increased frequency with which debris and hyperconcentrated flows occur, and the impact they have both on the environment and human life, merit close attention. This paper presents a numerical simulation using the FLO-2D model to predict areas potentially endangered by debris flows in Hualien County, Taiwan. The main conclusions which can be drawn from this study are as follows:

1. The modelling procedures using FLO-2D for delineation of risk areas induced by debris flow were established. The model verification results indicate that the FLO-2D model can successfully replicate the influence zone of the past debris-flow event with an acceptable error and demonstrate a better result than the empirical model adopted by the Soil and Water Conservation Bureau of Taiwan.

2. This study introduced the HSPF model to produce an inflow hydrograph from a watershed and compared its results with that of the FLO-2D rainfall-runoff model. The result shows the HSPF model has a better performance than the FLO-2D model at peak flow and flow recession periods. Thus, the HSPF model can be incorporated into the FLO-2D model to enhance the accuracy of debris flow simulation.

3. The sensitivity analysis shows that the parameters for the yield stress, roughness coefficient $n$ and volumetric sediment concentration have significant effects on the simulation results. For those parameters, proper values should carefully be given in debris-flow simulation in order to maintain a reliable computational result.

4. The calibration results for the yield stress from the three case studies indicate that this parameter tends to increase with the gradient of the debris flow fan apex. However, the rule can only be applied to creeks with lithology of metamorphic rocks. Further case studies are needed to verify the finding.

5. This verified model appeared to be capable of predicting and delineating potentially hazardous zones approximately associated with debris flows for a selected frequency design flood event, which would be very helpful in understanding the extent of debris flow inundation in extreme climatic events, as well as developing emergency plans and disaster management policies.

Acknowledgements. The study was supported by a grant from the Hualien Office of Soil and Water Conservation Bureau, the Council of Agriculture and the Executive Yuan, Taiwan. The authors would also like to acknowledge all the individuals who participated in the field data collections and investigation of debris flows associated with the Typhoon Fenghung.
Edited by: M. Arattano

Reviewed by: B. Zanuttigh and another anonymous referee

\section{References}

Arattano, M., Franzi, L., and Marchi, L.: Influence of rheology on debris-flow simulation, Nat. Hazards Earth Syst. Sci., 6, 519528, 2006, http://www.nat-hazards-earth-syst-sci.net/6/519/2006/.

Cetina, M.: Two-dimensional modelling of free surface flow, Acta hydrotechnica, University of Ljubljana, 18(29), 23-27, 2000.

Cetina, M., Rajar, R., Hojnik, T., Zakrajsek, M., Krzyk, M., and Mikos, M.: Case study: numerical simulations of debris flow below Stoze, Slovenia, J. Hydraul. Eng.-ASCE, 132(2), 121-130, 2006.

CSWCS (Chinese Soil and Water Conservation Society): Technical manual for soil and water conservation, Chinese Soil and Water Conservation Society, Taipei, Taiwan, 2003.

Garcia, R. and Lopez, J. L.: Debris flows on December 1999 in Venezuela, in: Chapter 20 of Debris-flow Hazards and Related Phenomena, edited by: Jakob, M. and Hungr, O., Springer Verlag Praxis, Berlin, 2005.

Han, G. and Wang, D.: Numerical modelling of Anhui debris flow, J. Hydraul. Eng.-ASCE, 122(5), 262-265, 1996.

Iketani, H. and Uehara, S.: Study on sediment control and prevention, Sedimentation Prevention, 114, 37-44, 1980.

Johanson, R. C., Imhoff, J. D., and Davis Jr., H. H.: Users manual for hydrological simulation program - Fortran (HSPF), Environmental Research Laboratory, EPA-600/9-80-015, Athens, Ga, 1980.

Julien, P. Y. and O'Brien, J. S.: Selected notes on debris flow dynamics, Recent developments on debris flows, Lecture note in earth sciences, Springer, Berlin, 144-162, 1997.

Laigle, D. and Coussot, P.: Numerical modelling of mudflows, J. Hydraul. Eng., 123(7), 617-623, 1997.

Lin, G. F., Chen, L. H., and Lai, J. N.: Reliability-based delineation of debris-flow deposition areas, Nat. Hazards, 32(3), 395-412, 2004.

Lin, M.-L., Wang, K.-L., and Huang, J.-J.: Debris flow run off simulation and verification - case study of Chen-You-Lan Watershed, Taiwan, Nat. Hazards Earth Syst. Sci., 5, 439-445, 2005, http://www.nat-hazards-earth-syst-sci.net/5/439/2005/.

Ming, J. and Fread, D. L.: Modeling of mud/debris unsteady flows, J. Hydraul. Eng.-ASCE, 125(8), 827-834, 1999.

O'Brien, J. S., Julien, P. Y., and Fullerton, W. T.: Two-dimensional water flood and mudflow simulation, J. Hydraul. Eng.-ASCE, 119(2), 244-261, 1993.

O'Brien, J. D.: FLO-2D user's manual, Version 2006.01, FLO Engineering, Nutrioso, 2006.

Petrascheck, A. and Kienholz, H.: Hazard assessment and mapping of mountain risks in Switzerland, in: Debris-flow Hazards Mitigation: Mechanics, Prediction, and Assessment, Proceedings 3rd International DFHM Conference, Davos, Switzerland, edited by: Rickenmann, D. and Chen, C.-L., Millpress, Rotterdam, 25-38, 2003.

Rickenmann, D. and Koch, T.: Comparison of debris flow modeling approaches, in: Debris-flow Hazards Mitigation: Mechanics, Prediction, and Assessment, Proceedings 1st International 
DFHM Conference, San Francisco, CA, edited by: Chen, C.L., American Society of Civel Engineers, New York, 576-585, 1997.

Rickenmann, D.: Empirical relationships for debris flows, Nat. Hazards, 19, 47-77, 1999.

Rickenmann, D., Laigle, D., Lamberti, A., Zanuttigh, B., Armanini, A., Fraccarollo, L., Giuliani, M., Rosati, G., McArdell, B. W., $\mathrm{Ng}$, D., Swartz, M., and Graf, C.: Evaluation of existing numerical simulation models for debris flow, Report on work package 3 of the research project THARMIT of the European Union, EU Contract EVG1-CT-1999-00012, EU, Brussels, 2003.

Shieh, C. L. and Tsai, Y. F.: Experimental study on the configuration of debris-flow fan, in: Proceedings of the First International Conference on Debris-flow Hazards Mitigation: Mechanics, Prediction and Assessment, San Francisco, California, 133$142,1997$.
Sinotech Engineering Consultants, Inc.: Study on delineation of debris-flow hazard zone and damage assessment in Hualien District, Hualien office, the Soil and Water Conservation Bureau, Hualien, Taiwan, 2007.

Sosio, R., Crosta, G. B., and Frattini, P.: Field observations, rheological testing and numerical modelling of a debris-flow event, Earth Surf. Proc. Land., 32, 290-306, 2007.

Takahashi, T.: Debris Flow, A.A. Balkema Publishers, Rotterdam, Netherlands, 1991.

Takahashi, T.: Mechanics and simulations of snow avalanches, proclastic flows and debris flows, Particulate gravity currents, in: Special Publication Int. Association of Sedimentologists, No. 31, edited by: McCaffrey, W. D., Kneller, B. C., and Peakall, J., Backwell Science, Oxford, UK, 11-43, 2001. 